\title{
Inhibition of in-vitro fertilization of hamster oocytes by a thiol proteinase inhibitor
}

\author{
S. Ichikawa, Y. Takehara, T. Shibata, H. Tamada, K. Oda* and S. Murao* \\ Laboratory of Animal Reproduction and ${ }^{*}$ Laboratory of Applied Microbiology, \\ College of Agriculture, University of Osaka Prefecture, Sakai City, Osaka 591, Japan
}

\begin{abstract}
Summary. Amongst the proteinase inhibitors tested, thiolstatin, a specific inhibitor for the thiol proteinases, leupeptin and antipain, both specific inhibitors of serine- and thiol-proteinases, strongly reduced fertilization of hamster oocytes in vitro. These results suggest the possible involvement of thiol proteinase(s), as well as acrosin, in the fertilization process. A possible role for thiol proteinase in sperm adhesion to the zona pellucida is proposed.
\end{abstract}

\section{Introduction}

The existence of a trypsin-like enzyme in mammalian spermatozoa has been recognized since the initial report by Yamane (1935). The enzyme has been named 'acrosin' (Zaneveld, Robertson, Kessler \& Williams, 1971) and 'acrosomal proteinase' (EC 3.4.21.10). Because natural and synthetic acrosin inhibitors interfere in vitro and in vivo with fertilization in rabbits (Stambaugh, Brackett \& Mastroianni, 1969; Zaneveld et al., 1971), hamsters (Miyamoto \& Chang, 1973) and mice (Bhattacharyya, Goodpasture \& Zaneveld, 1979), it has been suggested that acrosin is required for sperm penetration through the egg investments, especially the zona pellucida. However, purified ram acrosin derived from several million spermatozoa did not remove the zona pellucida from sheep eggs (Brown, 1982), whereas penetration of the zona by the fertilizing spermatozoon requires only a few minutes. The role of acrosin in sperm penetration of zona pellucida is therefore still inconclusive (Morton, 1977).

The present study was designed to investigate proteinases, other than acrosin, which may participate in fertilization of hamster egg, by utilizing various microbial proteinase inhibitors.

\section{Materials and Methods}

Preparation of capacitated sperm suspension. Epididymal spermatozoa were obtained from each cauda epididymidis of 100-150-day-old male hamsters, suspended in a $300 \mu \mathrm{l}$ drop of medium (see below) placed on a Petri dish at a concentration of $1 \cdot 0-10 \times 10^{6} / \mathrm{ml}$, and incubated for $3 \mathrm{~h}$ at $37^{\circ} \mathrm{C}$ under $5 \% \mathrm{CO}_{2}$ in air. During this time sperm counts were made. At the end of the incubation almost all spermatozoa showed whiplash motility, indicating the occurrence of capacitation. In a preliminary experiment the percentage fertilization was highest when sperm concentrations were $0.5-1.5 \times 10^{5} / \mathrm{ml}$. The capacitated sperm suspension was afterwards diluted with medium to a concentration of $1 \times 10^{5} / \mathrm{ml}$ for insemination.

Insemination. Female hamsters, 25-37 days of age, were treated with 30 i.u. PMSG and 25 i.u. hCG $48 \mathrm{~h}$ later. The oviducts were removed $15-18 \mathrm{~h}$ after hCG injection, placed under paraffin oil in a Petri dish, and the cumulus cell mass containing eggs in the ampulla was transferred through a tubal puncture into a drop of $200 \mu$ of the capacitated sperm suspension in the Petri dish. The dish was then incubated at $37^{\circ} \mathrm{C}$ under $5 \% \mathrm{CO}_{2}$ in air for $5 \mathrm{~h}$. Collection of spermatozoa and eggs and insemination were performed aseptically. 
Medium for capacitation and insemination. The medium used for capacitation and insemination was a modified Tyrode's solution containing $0.1 \mathrm{~mm}$-sodium pyruvate, 100 units penicillin and one third volume of female rat serum. The serum was heated at $56^{\circ} \mathrm{C}$ for $30 \mathrm{~min}$ before use. The medium was sterilized by millipore filtration (pore size, $0.45 \mu \mathrm{m}$ ). Medium drops were placed on a Petri dish (i.d. $50 \mathrm{~mm}$ ) and covered with sterilized liquid paraffin oil (Nakarai Chemical Co., Japan) which was equilibrated with the gas phase of $5 \% \mathrm{CO}_{2}$ in air after sterilizing. Medium drops were equilibrated at $37^{\circ} \mathrm{C}$ with the gas phase for $1 \mathrm{~h}$ before use.

Examination of fertilized eggs. After incubation, eggs were mounted in a small volume of the medium under a coverslip supported on four spots of a mixture of paraffin wax and vaseline, and examined under a microscope $(\times 400)$. Since male and female nuclei in fertilized eggs have proceeded to the pronucleus stage at the end of a 5-h incubation, the presence of pronuclei was used as the criterion for fertilization. Eggs which contained 3 or more pronuclei were classified as polyspermic. The number of spermatozoa adhering to each ovum was counted. The significance of the difference in fertilization rate (no. of eggs fertilized/no. of eggs examined) and the rate of polyspermy (no. of polyspermic eggs/no. of fertilized eggs) between control and experimental groups was tested with a $\chi^{2}$ test or Fisher's exact probability test.

Proteinase inhibitors. The proteinase inhibitors used in this study were the same as those used in a previous report (Ichikawa, Morioka, Ohta, Oda \& Murao, 1983). $\alpha$-MAPI, antipain and chymostatin were dissolved in $100 \%$ dimethylsulphoxide (DMSO) and the remaining inhibitors were dissolved in saline $(8.5 \mathrm{~g} \mathrm{NaCl} / 1)$ at appropriate concentrations. The final concentrations of DMSO and saline in the insemination medium were always $0.5 \%$ and $5 \%$ respectively. The inhibitor solutions were added to the sperm suspensions immediately before insemination at a final concentration between 1 and $160 \mu \mathrm{M}$.

\section{Results}

\section{Effects of proteinase inhibitors on fertilization}

Amongst the proteinase inhibitors examined leupeptin, thiolstatin and antipain exhibited strong inhibitory effects on fertilization and also reduced polyspermy. (Table 1). The percentages of fertilization and polyspermic eggs of DMSO controls were significantly greater than those of the saline controls. DMSO seems to influence the zona pellucida and facilitate sperm penetration. Nevertheless, at a concentration of $0.04 \mathrm{mM}$, the percentage fertilization was lowest for the eggs treated with antipain. $\alpha$-MAPI exhibited a lesser, but significant, effect. Pepstatin, E-64, and chymostatin had no effect upon fertilization at a concentration of $0.16 \mathrm{~mm}$.

All of the ova examined were entirely free of follicular cells and corona radiata. They were surrounded with zona pellucida and had no supplementary spermatozoa in the perivitelline space.

Of 304 ova treated with effective proteinase inhibitors $68 \%$ had no spermatozoa adhering to the zona surface, whereas only $3 \%$ of control ova and $7 \%$ of ova treated with ineffective inhibitors were free of adhering spermatozoa (Table 2). The number of spermatozoa adhering to one ovum ranged from 1 to more than 30 , and there was no dissimilarity in the number of adhering spermatozoa whether ova were treated with effective inhibitors or not.

\section{Time required for the thiol proteinase action during in-vitro fertilization}

Thiolstatin was added to the insemination medium at a final concentration of $0 \cdot 16 \mathrm{~mm} 1-15 \mathrm{~min}$ after insemination, and the ova were examined $5 \mathrm{~h}$ later. When the inhibitor was added $1 \mathrm{~min}$ after insemination, penetration was blocked in all 8 ova, but the addition of inhibitor 3 min later permitted penetration of $8 / 46(17 \%)$ ova. When the inhibitor was added $15 \mathrm{~min}$ after insemination, the percentage penetration $(20 / 23,87 \%)$ reached the control level $(30 / 36,83 \%)$. 
Table 1. Inhibition of in-vitro fertilization of hamster ova by proteinase inhibitors

\begin{tabular}{|c|c|c|c|c|}
\hline \multirow[b]{2}{*}{ Group } & \multirow[b]{2}{*}{ Proteinase inhibitor } & \multicolumn{3}{|c|}{ No. of eggs } \\
\hline & & Examined & Fertilized $(\%)$ & $\begin{array}{c}\text { Poly- } \\
\text { spermic }(\% *)\end{array}$ \\
\hline \multicolumn{5}{|c|}{ Inhibitors dissolved in saline } \\
\hline 1 & Control (saline) & 167 & $137(82)$ & $47(34)$ \\
\hline 2 & $0 \cdot 16 \mathrm{mM}-\mathrm{S}-\mathrm{PI}$ & 58 & $45(78)$ & $13(29)$ \\
\hline 3 & $0.08 \mathrm{~mm}$-Leupeptin & 40 & $3(8)^{a}$ & $0(0)$ \\
\hline 4 & $0.04 \mathrm{~mm}$-Leupeptin & 58 & $7(12)^{a}$ & $0(0)$ \\
\hline 5 & $0.04 \mathrm{~mm}$-Thiolstatin & 55 & $6(11)^{a}$ & $0(0)$ \\
\hline 6 & $0.01 \mathrm{~mm}$-Thiolstatin & 42 & $9(21)^{a}$ & $1(11)$ \\
\hline 7 & $0.001 \mathrm{~mm}$-Thiolstatin & 44 & $33(75)$ & $15(45)$ \\
\hline 8 & $0.16 \mathrm{~mm}-\mathrm{E}-64$ & 57 & $45(79)$ & $6(13)^{a}$ \\
\hline 9 & $0.04 \mathrm{~mm}-\mathrm{E}-64$ & 56 & $41(73)$ & $12(29)$ \\
\hline \multicolumn{5}{|c|}{ Inhibitors dissolved in $0.5 \%$ DMSO } \\
\hline 10 & Control (DMSO) & 123 & $115(93)^{\mathrm{a}}$ & $69(60)^{a}$ \\
\hline 11 & $0.16 \mathrm{mM}-\alpha-\mathrm{MAPI}$ & 51 & $32(56)^{b}$ & $11(34)^{c}$ \\
\hline 12 & $0.16 \mathrm{~mm}-$ Chymostatin & 57 & $48(84)$ & $24(50)$ \\
\hline 13 & $0.16 \mathrm{~mm}$-Antipain & 41 & $4(10)^{b}$ & $0(0)^{c}$ \\
\hline 14 & $0.04 \mathrm{~mm}$-Antipain & 68 & $2(3)^{\mathrm{b}}$ & $0(0)$ \\
\hline
\end{tabular}

$* \%$ in relation to fertilized eggs.

a Different from Group $1, P<0.01 ;^{\text {b }}$ different from Group $10, P<0.01 ;^{\circ}$ different from Group $10, P<0.05$.

Table 2. Percentage distribution of sperm-free and sperm-attached oocytes (fertilized and unfertilized) after incubation with strong blockers and ineffective inhibitors for $5 \mathrm{~h}$

\begin{tabular}{|c|c|c|c|c|c|}
\hline \multirow[b]{3}{*}{ Treatment } & \multirow{3}{*}{$\begin{array}{c}\text { No. of } \\
\text { oocytes } \\
\text { examined }\end{array}$} & \multicolumn{4}{|c|}{ Percentage of ova } \\
\hline & & \multicolumn{2}{|c|}{ Fertilized } & \multicolumn{2}{|c|}{ Unfertilized } \\
\hline & & Sperm-attached & Sperm-free & Sperm-attached & Sperm-free \\
\hline $\begin{array}{l}\text { Control } \\
\text { (saline and DMSO) }\end{array}$ & 290 & 86 & 1 & 11 & 2 \\
\hline $\begin{array}{l}\text { Ineffective } \\
\text { inhibitors } \\
\text { Fffective }\end{array}$ & $228^{*}$ & 76 & 3 & 18 & 4 \\
\hline inhibitors & $304 t$ & 4 & 6 & 28 & 62 \\
\hline
\end{tabular}

* Includes oocytes treated with S-PI, E-64 and chymostatin.

$\dagger$ Includes oocytes treated with leupeptin, thiolstatin and antipain.

\section{Effect of proteinase inhibitors on sperm motility}

Thiolstatin, leupeptin, antipain and $\alpha$-MAPI were added to sperm suspensions $\left(1 \times 10^{5} / \mathrm{ml}\right)$ at a final concentration of $0.16 \mathrm{mM}$. DMSO was added at a concentration of $0.5 \%$. The suspensions were incubated for $15 \mathrm{~min}$ and then examined. Neither the inhibitors nor the DMSO had any visible effect on sperm motility.

\section{Discussion}

Thiolstatin which is isolated from Bacillus sp. (Nakatani, Shin, Hayashi, Oda \& Murao, 1983) is a specific inhibitor for thiol proteinases, but not for serine proteinases. The strong inhibition of 
Table 3. Antifertility activity and anti-enzyme activity of serine and thiol proteinase inhibitors

\begin{tabular}{|c|c|c|c|c|c|}
\hline & Antipain & Leupeptin & $\alpha$-MAPI & Chymostatin & Thiolstatin \\
\hline \multicolumn{6}{|l|}{$\%$ of fertilized } \\
\hline eggs at $0.04 \mathrm{~mm}^{*}$ & 3 & 12 & $56 \dagger$ & $84 \dagger$ & 11 \\
\hline \multicolumn{6}{|l|}{$\mathrm{ID}_{50}(\mu \mathrm{g} / \mathrm{ml})$} \\
\hline Papain & $0 \cdot 19$ & $0 \cdot 30$ & 0.26 & 0.78 & 0.29 \\
\hline Trypsin & $3 \cdot 2$ & 4.9 & $>250$ & $>250$ & $>250$ \\
\hline Chymotrypsin & $>250$ & $>500$ & 0.75 & 1.43 & $>250$ \\
\hline
\end{tabular}

* Cited from Table 1.

+ Determined at $0.16 \mathrm{~mm}$.

$\operatorname{ID}_{50}(50 \%$ inhibition concentration) to trypsin and papain were determined with 0.7 mm-benzoyl-arginineparanitroaniline as substrate in $0.05 \mathrm{~m}$-Tris- $\mathrm{HCl}$ buffer $\mathrm{pH} 7.5$, and ID $_{50}$ to chymotrypsin with $0.5 \mathrm{~mm}$-benzoyltyrosine-paranitroaniline in $0.05 \mathrm{M}-\mathrm{T}$ ris $-\mathrm{HCl}$ buffer, $\mathrm{pH} 7 \cdot 5$, containing $30 \%$ acetone, at $50 \mu \mathrm{g}$ enzyme concentration.

fertilization of hamster eggs by thiolstatin in vitro indicates that a thiol proteinase is also indispensable for hamster egg fertilization.

When antifertility activities, estimated by percentage of fertilized eggs, of proteinase inhibitors were compared with their $50 \%$ inhibition concentrations $\left(\mathrm{ID}_{50}\right)$, antifertility activity and antipapain activity of antipain and leupeptin were similar to the values of thiolstatin (Table 3). This finding suggests that the antifertility effects of antipain and leupeptin are the result of inhibition of thiol proteinase. Acrosin is generally accepted as a zona-penetration enzyme and confirmed as a serine proteinase; acrosin isolated from boar spermatozoa is inhibited by di-isopropyl fluorophosphate, a specific inhibitor of serine proteinases and not of thiol proteinases (Polakoski \& McRorie, 1973). However, the $\operatorname{ID}_{50}$ values of antipain and leupeptin to trypsin were about 16 times the $\mathrm{ID}_{50}$ value to papain (Table 3). Therefore, inhibition of egg fertilization by antipain and leupeptin can be ascribed mostly to inhibition of the thiol proteinase and partly to inhibition of acrosin.

E-64 had no effect on fertilization, although it is a specific inhibitor of thiol proteinases (Hanada et al., 1978). The failure of E-64 to act may be due to the enzyme specificity. A similar difference in enzyme specificity was observed between the chymotrypsin and trypsin inhibitors: the $\mathrm{ID}_{50}$ value to papain of $\alpha$-MAPI and chymostatin was as low as any value of antipain and leupeptin, but $\alpha$-MAPI and chymostatin exhibited weak or no effect on egg fertilization, whereas the trypsin inhibitors strongly inhibited fertilization (Table 3).

Denudation of follicular cells and corona radiata from all ova treated with effective proteinase inhibitors indicates that they did not prevent sperm penetration through the cement substances surrounding the follicular cells. Furthermore, no spermatozoon was observed in the perivitelline spaces of ova treated with thiolstatin, as was the case with ova treated with leupeptin, antipain or $\alpha$ MAPI. These observations suggest that sperm penetration of the zona is the critical step at which the thiol proteinase functions. When strong inhibitors, such as thiolstatin, leupeptin and antipain, were added to the insemination medium, the percentage of sperm-free ova was significantly higher than with controls and groups treated with ineffective inhibitors. This finding suggests that the thiol proteinase may act on the initial attachment of the spermatozoon to the zona pellucida, as has been proposed for acrosin (Bhattacharyya \& Zaneveld, 1982).

A possible role for acrosin on the dispersion of the acrosomal matrix in the acrosome reaction during mouse and guinea-pig fertilization has been proposed (Fraser, 1982; Perreault, Zirkin \& Rogers, 1982). The present results cast no light on the question whether the thiol proteinase functions by dispersing the acrosomal matrix or by lysing a passage for the spermatozoon through the zona pellucida. This question remains for future study.

We thank Dr Walter G. Wiest of Department of Obstetrics \& Gynecology, Washington University, St Louis, for editorial help in the preparation of the manuscript. 


\section{References}

Bhattacharyya, A.K. \& Zaneveld, L.J.D. (1982) The sperm head. In Biochemistry of Mammalian Reproduction, pp. 119-151. Eds L. J. D. Zaneveld \& R. T. Chatterton. John Wiley \& Sons, New York.

Bhattacharyya, A.K., Goodpasture, J.C. \& Zaneveld, L.J.D. (1979) Acrosin of mouse spermatozoa. Am. J. Physiol. 237, E40-E44.

Brown, C.R. (1982) Effects of ram sperm acrosin on the investments of sheep, pig, mouse and gerbil eggs. $J$. Reprod. Fert. 64, 457-462.

Fraser, L.R. (1982) $p$-Aminobenzamidine, an acrosin inhibitor, inhibits mouse sperm penetration of the zona pellucida but not the acrosome reaction. $J$. Reprod. Fert. 65, 185-194.

Hanada, K., Tamai, M., Yamagishi, M., Ohmura, S., Sawada, J. \& Tanaka, I. (1978) Isolation and characterization of E-64, a new thiol protease inhibitor. Agric. Biol. Chem. 42, 523-528.

Ichikawa, S., Morioka, H., Ohta, M., Oda, K. \& Murao, S. (1983) Effect of various proteinase inhibitors on ovulation of explanted hamster ovaries. J. Reprod. Fert. 68, 407-412.

Miyamoto, H. \& Chang, M.C. (1973) Effects of protease inhibitors on the fertilizing capacity of hamster spermatozoa. Biol. Reprod. 9, 533-537.

Morton, D.B. (1977) The occurrence and function of proteolytic enzymes in the reproductive tracts of mammals. In Proteinases in Mammalian Cells and Tissues, pp. 445-500. Ed. A. J. Barrett. NorthHolland Publ. Co., Amsterdam.

Nakatani, S., Shin, T., Hayashi, H., Oda, K. \& Murao, S. (1983) Purification of a thiol proteinase inhibitor, thiolstatin, isolated from Bacillus sp., and its properties. Proc. agric. chem. soc. Japan, p. 510, Abstr. (In Japanese.)

Perreault, S.D., Zirkin, B.R. \& Rogers, B.J. (1982) Effect of trypsin inhibitors on acrosome reaction of guinea pig spermatozoa. Biol. Reprod. 26, 343-351.

Polakoski, K.L. \& McRorie, R.A. (1973) Boar acrosin. II. Classification, inhibition, and specificity studies of a proteinase from sperm acrosomes. J. biol. Chem. 248, 8183-8188.

Stambaugh, R., Brackett, B.G. \& Mastroianni, L. (1969) Inhibition of in-vitro fertilization of rabbit ova by trypsin inhibitors. Biol. Reprod. 1, 223-227.

Yamane, J. (1935) Kausal-analytische Studien ueber die Befruchtung des Kanincheneies. I and II. Cytologia 6, 234-256 and 474-484.

Zaneveld, L.J.D., Robertson, R.T., Kessler, M. \& Williams, W.L. (1971) Inhibition of fertilization in vivo by pancreatic and seminal plasma trypsin inhibitors. J. Reprod. Fert. 25, 387-392.

Received 27 March 1984 